\title{
Building Inter-Organizational Social Capital Instruments to Evaluate Collaborative Networks
}

\author{
Janaina Macke ${ }^{1}$, Rolando Vargas Vallejos ${ }^{2}$, Eduardo Dalpiccoli Toss ${ }^{1}$ \\ ${ }^{1}$ Universidade de Caxias do Sul, Rio Grande do Sul, Brasil; ${ }^{2}$ Faculdade de Tecnologia TECBrasil, Porto Alegre, Brasil. \\ Email: jmacke@terra.com.br, \{rolandovvallejos, tosspuc\}@hotmail.com
}

Received October $20^{\text {th }}, 2009$; revised November $29^{\text {th }}, 2009$; accepted December $30^{\text {th }}, 2009$.

\begin{abstract}
This paper presents the development process of an inter-organizational social capital survey to evaluate collaborative networks. The survey instrument construction was based on three main sources. The first one, was a deep literature research that covered social capital and collaborative network issues. The second, a meta-analysis from well-known journals basically taken from the Business Source Premier Database. Finally, the third, was an exploratory research done in a Brazilian enterprise collaborative network. In this exploratory phase, we used semi-structured interviews, direct observation and document analysis. As a result of this work, we present two instruments for inter-organizational social capital evaluation: a qualitative instrument, built in the first stage of the study and a quantitative instrument (survey) built from the results of the exploratory phase.
\end{abstract}

Keywords: Interorganizational Social Capital, Collaborative Networks, Qualitative Instrument, Survey Instrument, Brazil

\section{Introduction}

In the south of Brazil, micro and small businesses represent $94.9 \%$ of formal businesses, occupying about $63 \%$ of jobs [1]. In most cases, these small companies, because of their size, face many difficulties because they do not have competitive skills and resources. In this sense, is important to create mechanism to enhance their development and consequently the development of the region.

Considered as one of the emerging forms of management, collaboration between competitors can happen it in different ways. The focus of this work is in cooperation through collaborative networks. The initiative for studies on these new forms of management is more significant in the European Community, where there are several projects, among them the ECOLEAD (European Collaborative Networked Organizations Leadership Initiative), projects such as the German and Swiss Virtuelle Fabrik, in Portugal there are the TeleCare (Tele-Supervision System for Elderly Care), the PRODNET-II (Production Planning and Management in the Extended Enterprise) and COVE (Cooperation Infrastructure for Virtual Enterprises and Electronic Business). In France there is the project ATHENA (Advanced Technologies for Interoperability of Heterogeneous Enterprise Networks and Applications) and in England the project EC-NET (Concurrent Enterprising Network of Excellence).
There are also important research and projects in this area outside Europe. Some examples are the American NIIIP (National Industrial Information Infrastructure Protocols), the Japanese Industrial Cluster (Japan) and the project Virtual Industry Cluster (Mexico). In Brazil, three major projects in the area may be cited: the VIRTEC, the Millennium Factory Institute (IFM) and the VIRFEBRAS, object of study of this paper.

At the University of Caxias do Sul (Serra Gaucha region, south of Brazil), two research groups may be related to the theme of social capital within a collaborative network: the "Enterprise Collaborative Networks Group" and the "Organizational Social Theory Group", in which researche includes social capital, social responsibility and local development. Both groups are registered in the $\mathrm{Na}-$ tional Council for Scientific and Technological Development (CNPq), in Brazil.

This work aims to build an instrument (survey) to evaluate inter-organizational social capital within a collaborative network. To achieve this main purpose, we did a preliminary (exploratory) research in an enterprise collaborative network in VIRFEBRAS network. In this exploratory phase, we used semi-structured interviews, direct observation and document analysis. We analyzed the social capital elements that influence the dynamics of the network and identified the local aspects related to the network competitiveness. So, it was possible to raise 
variables to build the survey instrument.

\section{Social Capital}

Social capital can be understood as a set of informal norms and values, common to the members of a specific group which allow the cooperation among them.

Since the concept of Social Capital emerged, it is being used to explain a lot of social phenomena; most of the researches have focused on the role of Social Capital in the human capital development [2,3], in the economic performance [4], in the development of regions [5] and in the development of countries [6].

In the study that relates capital to the creation of intellectual capital, Nahapiet and Ghoshal [7] propose three macro-dimensions of social capital: the structural, the relational and cognitive. For these authors social capital is the "sum of the actual and potential resources embedded within, available through and derived from the network of relationship possessed by an individual or social unit" [7].

Although they have made the analytical separation of the capital in three dimensions, the authors believe that there is a relationship between the great traits in each of them. The principal elements of each dimension are presented in Figure 1.

The structural dimension of Social Capital is related to: the presence or not of relationships between the actors, the configuration or morphology of the network describing the standards of connections through variables such as density, connectivity network configuration, stability and ties. The relational dimension describes the kind of personal relationship developed through a history of interactions. This concept focuses on aspects that influence behaviors as: trust and distrust, norms, obligations and expectations and identity. Finally, the cognitive dimension of social capital refers to the resources that emanate shared visions, interpretations and systems of meaning, mainly codes and narratives shared, values, and other cultural elements. Some authors affirm that this dimension is not being explored in the literature [7].

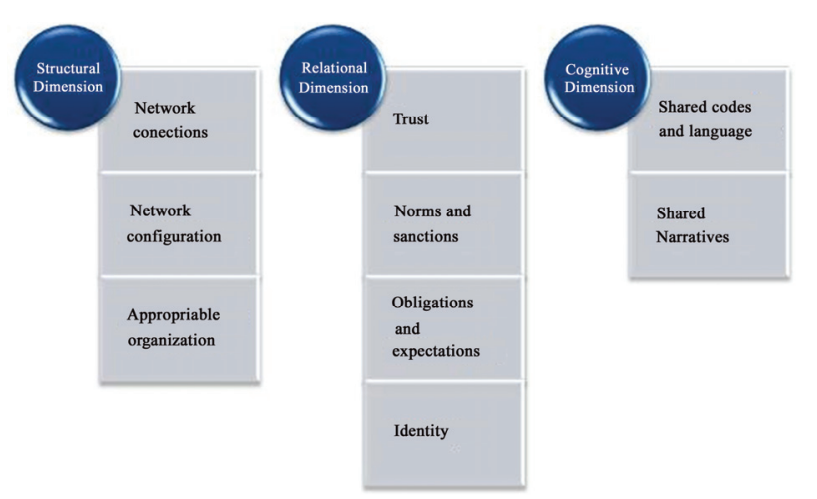

Figure 1. Social capital dimensions. Adapted from Nahapiet and Ghoshal [7]

\section{VIRFEBRAS: A Collaborative Network}

The establishment of cooperation between competitors can bring more benefits than confrontation if goals, interests and limits were defined in the early collaboration process. The goals may be different, some examples are: the development of products in search of suppliers, new markets, new technologies, the empowerment of people, etc. The interests may differ even between companies within the network [8].

This work has focused on emerging forms of cooperation, such forms are called collaborative networks that consists in entities (people and organizations) autonomous, geographically distributed and heterogeneous with respect to its environment of operation, their culture, their goals and their capital [9].

The VIRFEBRAS is a group of small and medium enterprises of the sector of industrial tools that work in combination with common goals while maintaining their own identities. Nowadays, seven companies are part of this network: Metallurgical Coprima LTDA, JR Oliveira, CJN Industry LTDA of Matrices, Matrices Sadel LTDA, Sildre, Inova Matrices and Roltex Polishing and Texturing Ltda. The idea of this association appeared in 1998 with the support of the Department of Mechanical Engineering (DEMC), of the University of Caxias do Sul (UCS).

In the exploratory phase we developed a qualitative instrument that was applied in nine companies-six members of VIRFEBRAS and three ex-members. The interviews had the following questions (see Figure 2).

In the content analysis, three main aspects can be highlighted. The first is a kind of lack of leadership, which was identified as a problem for all companies, participants and ex-participants. The social capital theory states that the horizontal relationships should be receive more attention, but, on the other hand, some networks can suffer from not having a more proactive member that feels responsibly for solving problems and promoting essential changes. Most networks in the Cooperation Network Program have the universities covering this lack.

The second aspect is a problem of network identity. In the specific case of VIRFEBRAS, an aspect related to this lack is that they do not have a physical place belonging to the network: the members had meetings in a different place each time (member's head office). One way to face this problem could be creating a community of practice, which allows to share and learn from each other by physical contact or virtual, with a goal or need to solve problems, share experiences, techniques or methodologies, to consider the provision of best practice [10].

The third and last point concerns the information exchanges. It is common for a network to find difficulties in sharing equally technical, human and conceptual skills (Katz [11] classifies business skills in these three categories). In most cases, one kind of skill is more shared than the others, like it happens in VIRFEBRAS, where most part of the information exchanged is technical. 
After content analysis, we used the software NVivo 8 to generate items of inter-organizational social capital. One of the tools we adopted was a matrix to verify the simultaneous occurrence of elements cited (see Figure 3).

Thus, the pairs of concepts that appear most in the interviews in VIRFERBRAS are: 1) "technical skills" and "technical information exchange", cited in six of the nine respondents; 2) "technical skills" and "time dedicated to the network, both cited in five of the nine interviews; and 3 ) "technical skills" and "leadership", cited in five of the nine interviews.
Therefore, the inter-organizational social capital survey was built in three sources. The first derived from literature review, specially the World Bank framework [12] and the Onyx and Bullen [13] instrument. The second source was a meta-analysis performed by Vallejos et al. [14], which emphases that the issue of social capital in the $\mathrm{CN}$ context is lack explored (although the word "trust" appears most of the time, it is related as an isolated concept and not as an element of social capital). And the third, was the qualitative research conducted in VIRFEBRAS.

\footnotetext{
1 - Tell a story about a business process carried out by your company within the Network.

2 - What issues do you believe facilitate network collaboration?

3 - What issues do you believe undermine network collaboration?

4 - How do you think the cooperation in a network should be?

5 - Do you believe that NETWORK should be redesigned? What elements do you believe are essential to this restructuring?

6 - A client offers your company a very favorable contract, involving significant profits for a long time, but you do not have capacity to meet the demands of this customer alone. Point out the name of three companies you would choose to work with you and comment the reasons for these choices.

7 - Has your company already asked for a help in the NETWORK?

8 - Are there rules for conducting of the business processes within the NETWORK?

9 - Point out some characteristics you think you have in common with other members of the NETWORK

10 - WhY have the ex-participants of VIRFEBRAS leave the association? (in the case of interviewing ex-participants: Why did your company decide to leave the Network?

11 - In your opinion, what made the ex-participants leave the NETWORK?

12 - Do you share experiences (about market, staff, customers, suppliers) with other members?

13 - Speak about one important experience you had in the NETWORK.
}

Figure 2. Qualitative instrument to evaluate inter-organizational social capital

\begin{tabular}{|c|c|c|c|c|c|c|c|c|c|c|c|c|}
\hline & 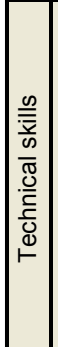 & 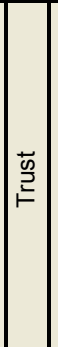 & 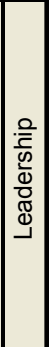 & 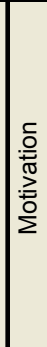 & 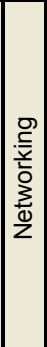 & 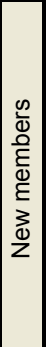 & 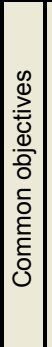 & 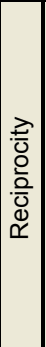 & 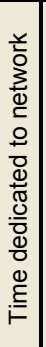 & 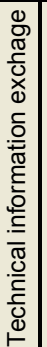 & 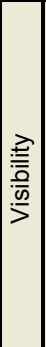 & 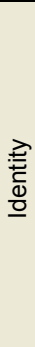 \\
\hline Technical skills & 8 & 3 & 5 & 3 & 3 & 3 & 1 & 2 & 5 & 6 & 2 & 4 \\
\hline Trust & 3 & 3 & 2 & 2 & 2 & 1 & 0 & 1 & 2 & 3 & 1 & 2 \\
\hline Leadership & 5 & 2 & 6 & 4 & 4 & 3 & 2 & 0 & 3 & 4 & 3 & 2 \\
\hline Motivation & 3 & 2 & 4 & 4 & 4 & 2 & 1 & 0 & 1 & 3 & 2 & 1 \\
\hline Networking & 3 & 2 & 4 & 4 & 4 & 2 & 1 & 0 & 1 & 3 & 2 & 2 \\
\hline New members & 3 & 1 & 3 & 2 & 2 & 4 & 2 & 1 & 2 & 2 & 1 & 2 \\
\hline Common objectives & 1 & 0 & 2 & 1 & 1 & 2 & 2 & 0 & 1 & 1 & 1 & 0 \\
\hline Reciprocity & 2 & 1 & 0 & 0 & 0 & 1 & 0 & 2 & 1 & 2 & 0 & 2 \\
\hline Time dedicated to network & 5 & 2 & 3 & 1 & 1 & 2 & 1 & 1 & 5 & 4 & 1 & 3 \\
\hline Technical information exchage & 6 & 3 & 4 & 3 & 3 & 2 & 1 & 2 & 4 & 7 & 3 & 4 \\
\hline Visibility & 2 & 1 & 3 & 2 & 2 & 1 & 1 & 0 & 1 & 3 & 3 & 1 \\
\hline Identity & 4 & 2 & 2 & 1 & 2 & 2 & $0 \mid$ & 2 & 3 & 4 & 1 & 5 \\
\hline
\end{tabular}

Figure 3. Matrix of elements in the exploratory phase 


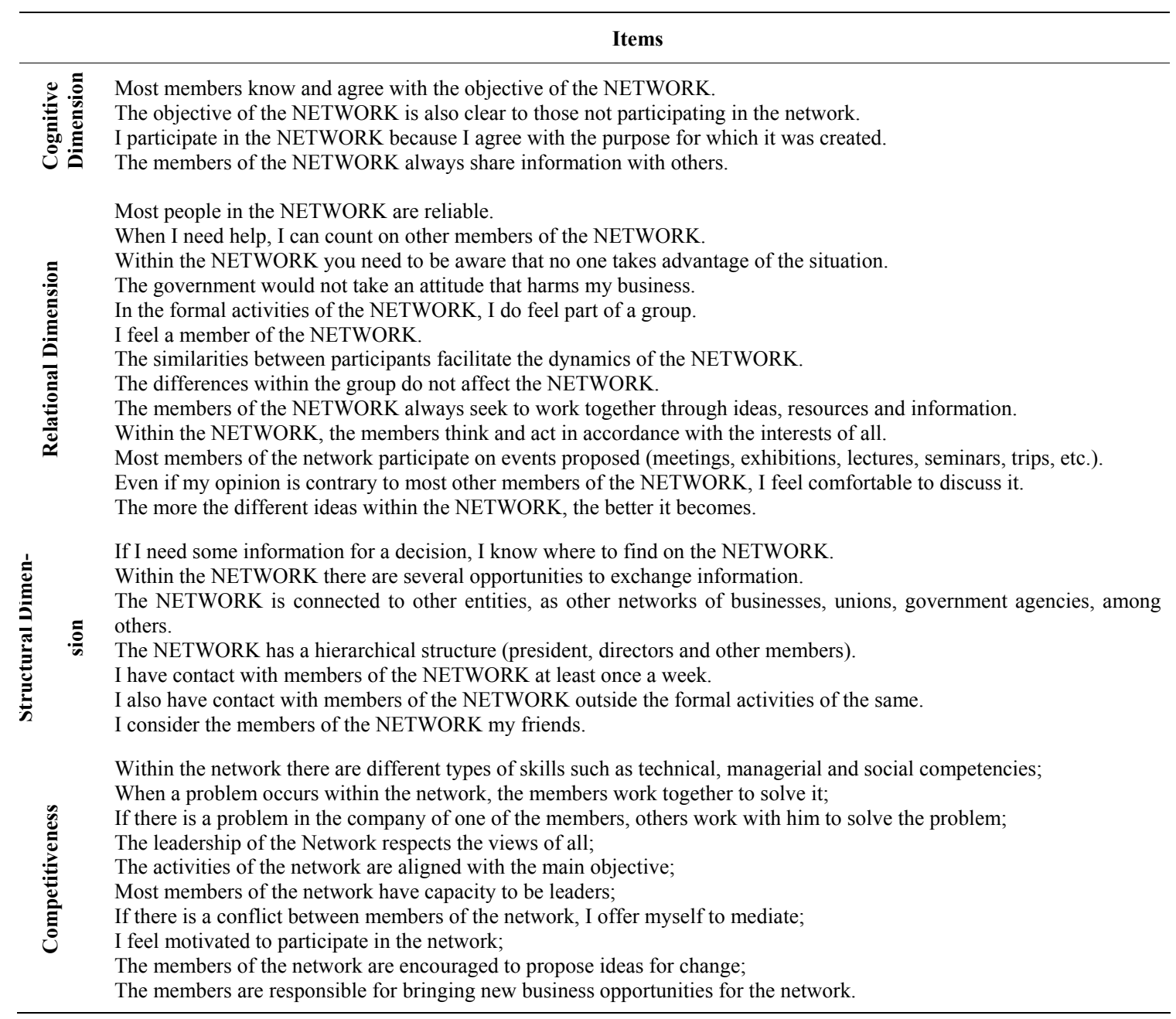

Figure 4. Items of social capital dimensions and competitiveness in inter-organizational environment

\section{Results}

In this section we present the survey items, according to the social capital dimensions. The exploratory phase also allows to indicate competitive variables (see Figure 4). It is important to notice that some peculiarities of local context must be observed before surveying the network.

The first key point is, besides social capital is strongly dependent on local context, it is possible suppose that his survey can be tested in many others collaborative networks. In fact, we are looking for foreigner researches, which are interested in test the instrument and make a cross-cultural research.

\section{Final Considerations}

Social Capital is a component of the Social Theory that is being considered as a key-element for the human and economic development of the communities. Some reasons that contribute for the interest in Social Capital are: the value of the social relations in social and economic discussions, the transformations of the society and the role of the State, the importance of network relations to improve economic performances and the need of concepts to understand the complexity of human being. The Social Capital can be understood as a set of informal norms and values, common to the members of a specific group, that allow the cooperation among them. Many authors point the difficulty to measure this concept; most of the time it is possible to measure the absence of Social Capital instead of its presence.

Considering Collaborative Networks $(\mathrm{CN})$ it is important to analyze the impact of their development and, consequently, evaluate aspects of their creation, operation, and dissolution. In other words, the exploitation and, even though, the generation of social capital are closely related on the programming of the groups qualification (induction) and in which way the agents manage the network. Therefore it is important to build instruments to evaluate inter-organizational social capital. 


\section{Acknowledgments}

This work is being supported by the University of Caxias do Sul (Universidade de Caxias do Sul-UCS), the Faculdade FTec Brasil, and the National Counsel for Scientific and Technological Development (Conselho Nacional de Desenvolvimento Científico e TecnológicoCNPq).

\section{REFERENCES}

[1] SEDAI (Secretaria do Desenvolvimento e Assuntos Internacionais do Rio Grande do Sul), "Redes de cooperação: A força da união," Porto Alegre, 2005.

[2] J. S. Coleman, "Foundations of social theory," Harvard University Press, Cambridge, 1990.

[3] G. Loury, "Why would we care about group inequality?" Social Philosophy \& Policy, Vol. 5, pp. 249-271, 1987.

[4] W. E. Baker, "Market networks and corporate behavior," American Journal of Sociology, Vol. 96, pp. 589-625, 1990.

[5] R. D. Putnam, R. Leonardi, and R. Y. Nanetti, "Making democracy work: Civic traditions in modern Italy," Princeton University Press, Princeton, 1993.

[6] F. Fukuyama, "Trust: The social creation virtues and the creation of prosperity," Free Press, New York, 1995.

[7] J. Nahapiet and S. Ghoshal, "Social capital, intellectual capital and the organizational advantage," Academy of Management Review, Vol. 23, No. 2, pp. 242-266, 1998.

[8] R. V. Vallejos, "Um modelo para formação de Empresas Virtuais no setor de moldes e matrizes," Ph.D. dissertation, Universidade Federal de Santa Catarina, 2005.

[9] L. M. Camarinha-Matos and H. Afsarmanesh, "Collaborative networks: A new scientific discipline," Journal of Intelligent Manufacturing, Springer, The Netherlands, No. 16, pp. 439-452, 2005.

[10] J. S. Brown and P. Duguid, "Organizational learning and communities-of-practice: Toward a unified view of working, learning and innovation," Organization Science, Vol. 2, No. 1, pp. 40-57, 1999.

[11] R. L. Katz, "Skills of an effective administrator," Harvard Business Review, Vol. 52, No. 5, pp. 90-102, September/October 1974.

[12] World Bank, Social Capital Assessment Toolkit, 2004 http://www1.worldbank.org/sp/ldconference/Materials/Pa ralle1/PS1/PS1_S1_PPT1.pdf.

[13] J. Onyx and P. Bullen, "Measuring social capital in five communities," The Journal of Applied Behavioral Science, Vol. 36, No. 1, pp. 23-42, 2000.

[14] R. V. Vallejos, J. Macke, P. M. Olea, and E. D. Toss, "Collaborative networks and social capital: A theoretical and practical convergence," Pervasive Collaborative Networks, Springer, Boston, Vol. 283, pp. 43-52, 2008. 